\title{
Perancangan Aplikasi E-contract Pada Platform Manga Toon Berbasis Web Pada Manga Toon HK Limited
}

\author{
Siti Maesaroh ${ }^{1}$, Danang Rifai ${ }^{2}$, Dyah Shafira Dewi ${ }^{3}$ \\ ${ }^{1,2,3)}$ Fakultas Sains dan Teknologi Universitas Raharja
}

Email: ${ }^{1}$ siti.maesaroh@ raharja.info, ${ }^{2}$ danang,rifai@ raharja.info, ${ }^{3}$ dyah.shafira@ raharja.info

\begin{abstract}
Abstrak
Pada zaman industri 4.0, banyak aplikasi atau web yang menyediakan layanan baca komik dan novel secara online, baik berbentuk e-book, aplikasi, maupun web yang memang menyediakan layanan tersebut. Manga Toon adalah salah satu platform penyedia layanan baca komik, novel, dan menonton anime online internasional. Manga Toon juga menyediakan tempat baca novel karya penulis lokal yang bebas dibaca dimanapun dan kapanpun. Author novel yang meng-upload karya memiliki kesempatan bisa mendapatkan penghasilan dari karya tersebut. Namun, sistem penerimaan kontrak di Manga Toon masih semi-komputerisasi, karena masih menghubungi author melalui nomor whatsapp yang sejak awal didaftarkan saat meng-upload karya, lalu menginput data ke surat kontrak secara manual yang dilakukan oleh admin. Kegiatan ini memakan waktu yang cukup banyak sehingga proses pembuatan surat kontrak dan pengiriman kembali surat kontrak yang sudah di approve terhambat. Dengan permasalahan tersebut, maka penulis melakukan analisa melalui beberapa metode pengumpulan data, dengan melakukan kegiatan magang/observasi, melakukan wawancara dan metode studi pustaka untuk menemukan solusi dari permasalahan yang terjadi pada penerimaan kontrak novel di aplikasi Manga Toon. Penulis akan menganalisis dengan menggunakan metode PIECES. Selanjutnya, desain sistem yang dibuat berjalan menggunakan Unified Modeling Language (UML) diantaranya menggunakan Use Case Diagram dan menggunakan Activity Diagram. Dalam hal ini, penulis menganalisa sistem kontrak pada aplikasi Manga Toon diharapkan dapat menggunakan sistem dalam penginputan data ke surat kontrak.
\end{abstract}

Kata Kunci--- Manga Toon, Kontrak novel, UML

\begin{abstract}
In industrial age 4.0, many applications or the web provide online comic and novel reading services, both in the form of e-books, applications, and the web that provide these services. Manga Toon is a platform that provides international comics, novels and streaming anime online service providers. Manga Toon also provides a place to read novels that are free to read wherever and whenever. Authors of novels who upload works have the opportunity to earn income from work. However, the contract acceptance system in Manga Toon is still semi-computerized, because it still contacts
\end{abstract}


the author via WhatsApp number, which was registered at the beginning when uploading the work, then manually entered data into the contract letter made by the admin. This activity takes a considerable amount of time so that the process of making contract letters and sending back contracts that have been approved is hampered. With these problems, the authors analyze through several data collection methods, namely conducting internships / observations, interviews and library methods to find solutions to problems that occur in the acceptance of novel contracts in the Manga Toon application. The author will analyze using the PIECES method. Furthermore, the system design that runs using the Unified Modeling Language (UML) includes use case diagrams, activity diagrams and sequence diagrams. In this case, the authors analyze the contract system in the Manga Toon application and are expected to use the system in inputting data to the contract letter.

Keywords: Manga Toon, Novel contract, UML

\section{PENDAHULUAN}

Perkembangan teknologi informasi memacu untuk memasuki era modern dalam kehidupan, Kehidupan seperti ini dikenal dengan e-life (electronic life), artinya dalam kehidupan ini sudah dipengaruhi oleh berbagai kebutuhan secara elektronik. Sekarang sedang semarak dengan berbagai huruf yang dimulai dengan awalan e, seperti e-commerce, e-government, e-library, e-journal, e-medicine, e-laboratory, serta yang lainnya lagi yang berbasis elektronik

Dewasa ini, banyak aplikasi atau web yang menyediakan layanan baca komik dan novel secara online, baik berbentuk e-book, aplikasi, maupun web yang memang menyediakan layanan tersebut. Manga Toon adalah salah satu platform penyedia layanan baca komik, novel, chat novel, dan menonton anime online internasional. Manga Toon juga menyediakan tempat baca novel karya penulis lokal yang bebas dibaca dimanapun dan kapanpun. Author yang meng-upload karya memiliki kesempatan bisa mendapatkan penghasilan dari karya tersebut. Manga Toon menyediakan tempat untuk mengajukan kontrak bagi author yang ingin mendapatkan pendapatan lebih besar dari hasil karya-nya.

\section{METODE PENELITIAN}

\section{Metode Pengumpulan Data}

\section{Observasi}

Metode observasi dilakukan secara pengamatan langsung pada kantor Manga Toon agar mendapat berbagai data yang diperlukan dalam penulisan dan membantu menganalisa untuk membangun sistem tersebut.

2.Metode Wawancara (Interview)

Selain melakukan kegiatan magang, penulis melakukan wawancara denganstakeholder yaitu kepada marketing manager kantor Manga Toon, dengan mengajukan beberapa pertanyaan mengenai kantor Manga Toon.

3. Metode Studi Pustaka 
Metode studi pustaka dilakukan dengan membaca dan mempelajari beberapa buku dan jurnal yang berhubungan dengan teori yang dibahas dalam laporan penelitian ini, mencari literatur di internet, serta membaca dan mempelajari kembali catatan kuliah yang dimiliki penulis.

\section{Identifikasi masalah}

1. Sistem penerimaan kontrak masih bersifat semi komputerisasi karena masih menginput data secara manual ke surat kontrak

2.Proses surat kontrak terhambat karena prosesnya dibuat secara manual dengan print-scan surat kontrak hingga dikembalikan ke author.

\section{TINJAUAN PUSTAKA}

\section{Definisi Sistem}

Menurut Uus Rusmawan (2019:7) ${ }^{[1]}$, "Sistem didefinisikan sebagai suatu jaringan atau komponen yang dapat membentuk kesatuan yang terkumpul untuk menyelesaikan suatu tujuan tertentu".

Menurut Ageng Setiani dkk pada jurnal CCIT Vol.8 No.3 $(2015: 49)^{[2]}$ berpendapat bahwa Sistem adalah suatu jaringan kerja dari produsen-produsen yang saling berhubungan berkumpul bersama-sama untuk melakukan suatu kegiatan atau untuk menyelesaikan suatu sasaran atau tujuan tertentu.

Dari pendapat ahli di atas dapat disimpulkan bahwa sistem merupakan kumpulan dari elemen-elemen yang saling berkaitan dan berkesinambungan yang terkumpul untuk menyelesaikan suatu tujuan yang sudah ditentukan.

\section{Definisi Informasi}

Menurut Barry E. Cushing dalam Yulia Djahir dan Dewi Pratitia $(2015: 9)^{[3]}$, "Informasi merupakan sesuatu yang menunjukkan hasil pengolahan data yang diorganisasi dan berguna kepada orang yang menerimanya".

Menurut Khozin Yuliana, dkk $(2017: 192)^{[4]}$ berpendapat bahwa informasi yaitu fakta yang telah diolah dengan cara tertentu, menggambarkan suatu kejadian nyata untuk diolah agar dapat dipahami dan digunakan dalam pengambilan suatu keputusan.

Dari beberapa pendapat ahli tersebut dapat disimpulkan bahwa informasi adalah sekumpulan dari data yang sudah diolah dan dapat menggambarkan suatu kejadian dari hasil yang diolah yang dapat berguna bagi penerima dan dapat digunakan sebagai pengambilan keputusan. 


\section{Definisi Author}

Menurut Agoes Soegianto (2018:17) $)^{[5]}$, Author adalah digunakan untuk sebutan bagi seorang penulis.

Menurut Rachmat Kriyantono (2014:225) ${ }^{[6]}$, Author memiliki arti yaitu individu yang memilih dan menyusun isi pesan yang disampaikan.

Menurut M Arafat Imam dan Kim-Ara (2016:233) ${ }^{[7]}$, Author adalah sebutan dalam bahasa inggris untuk menyebut seorang penulis fiksi / ilmiah.

Dari pendapat ahli di atas dapat disimpulkan bahwa definisi author yaitu sebutan bagi seorang penulis dalam bahasa inggris yang menulis karya ilmiah maupun fiksi dengan merangkai dan menyusun kata yang berupa isi pesan yang disampaikan dalam sebuah karya fiksi, maupun informasi dari penelitian ilmiah yang dilakukan.

\section{Definisi E-Contract}

Menurut Attorney Richard Stim (2016:151) ${ }^{[8]}$, E-Contract adalah perjanjian yang dibuat dan ditandatangani dalam bentuk elektronik; tidak ada kertas atau salinan cetak lainnya yang digunakan.

Menurut Benita Ezeigbo (2017:2) ${ }^{[9]}$ kontrak adalah segala jenis kontrak yang dibentuk dalam rangka perdagangan melalui interaksi dua atau lebih individu yang menggunakan rata-rata elektronik, seperti email, interaksi individu dengan agen elektronik, seperti program komputer, atau interaksi dari setidaknya dua agen elektronik yang diprogram untuk mengenali keberadaan suatu kontrak.

Dari pendapat ahli di atas dapat disimpulkan bahwa definisi Econtract yaitu perjanjian yang dibuat oleh 2 belah pihak yang tidak bertemu secara langsung dan perjanjiannya dilakukan melalui media elektronik.

\section{LITERATURE REVIEW}

1. Menurut penelitian yang telah dilakukan oleh Galuh Puspaningrum (2018:1) $)^{[10]}$ menuliskan bahwa E-Contract atau electronic contract merupakan perjanjian yang dilakukan melalui komputer dan internet yang dilakukan oleh satu atau lebih mengikatkan diri kepada orang lain untuk melakukan transaksi niaga. e-contract sebagai bentuk dari hubungan hukum antara pelaku usaha dengan konsumen. e-contract lahir dari perkembangan hukum kontrak di era globalisasi yang memiliki jangkauan yang luas bahkan hingga lintas negara. Sehingga subjek hukum dan objek hukum melibatkan hukum perdata internasional.

2. Menurut penelitian yang dilakukan oleh Biswajit Tripathy dan Jibitesh Mishra (2018) ${ }^{[11]}$ menuliskan bahwa Kontrak elektronik adalah bagian utama dari aktivitas e-commerce. Kontrak antara pihak yang bertukar telah diadopsi sebagai solusi yang menjamin hak peserta dan meningkatkan rasa saling 
percaya. Protokol Open Buying on the Internet (OBI) digunakan untuk perdagangan internet bisnis ke bisnis (B2B).

3. Menurut penelitian yang dilakukan oleh Emir Husni, Bramanto Leksono, Muhammad Ridho Rosa yang berjudul (2015) ${ }^{[12]}$ menuliskan bahwa Kontrak dalam perdagangan layanan sangat penting. Penandatanganan kontrak dapat memakan waktu dan proses yang mahal, terutama jika pembeli dan penjual jauh dari satu sama lain.

4. Menurut penelitian yang dilakukan Biswajit Tripathy dan Jibitesh Mishra (2017) ${ }^{[13]}$ menuliskan bahwa Kontrak elektronik adalah bagian utama dari aktivitas e-commerce. Kontrak elektronik (kontrak elektronik) atau perjanjian Mitra Dagang / Trading Partner agreement (TPA) dapat dilakukan antara pemangku kepentingan yang terlibat termasuk otoritas pembayaran, pembeli $\&$ penjual. Beberapa standar e-commerce perlu diintegrasikan agar memiliki kerangka kerja standar.

5. Menurut penelitian yang dilakukan oleh Himanshu Jain, P. Radha Krishna, dan Kamalakar Karlapalem(2016 $)^{[14]}$ menuliskan bahwa E-contract adalah kontrak yang ditentukan, dimodelkan dan dijalankan oleh sistem perangkat lunak. Proses bisnis E-contract dimodelkan menggunakan alur kerja dan pemberlakuannya sebagian besar tergantung pada konteks eksekusi. Sistem $e$-contract yang ada tidak memiliki kesadaran konteks, dan karenanya sering menghadapi kesulitan dalam memberlakukan ketika konteks dan persyaratan kontrak elektronik berubah pada saat run-time.

\section{Metode Analisis PIECES}

\section{HASIL DAN PEMBAHASAN}

Tabel 1. Analisis PIECES

\begin{tabular}{|l|l|l|}
\hline Analisa & Sistem Lama & Sistem yang Diinginkan \\
\hline Performance & $\begin{array}{l}\text { Sistem kerja yang dibebankan } \\
\text { kepada admin terlalu berat }\end{array}$ & $\begin{array}{l}\text { Beban admin diringankan } \\
\text { dengan adanya website yang } \\
\text { di-manage bersama dengan } \\
\text { approval }\end{array}$ \\
\hline Information & $\begin{array}{l}\text { Informasi mengenai kontrak } \\
\text { masih tidak jelas }\end{array}$ & $\begin{array}{l}\text { Informasi mengenai kontrak } \\
\text { dapat dipahami dengan mudah }\end{array}$ \\
\hline Economy & $\begin{array}{l}\text { Penggunaan kertas untuk surat } \\
\text { kontrak yang harus di scan } \\
\text { masih sangat boros }\end{array}$ & $\begin{array}{l}\text { Penggunaan otomatis export to } \\
\text { pdf file untuk surat kontrak } \\
\text { akan lebih menghemat kertas } \\
\text { cetak }\end{array}$ \\
\hline Control & $\begin{array}{l}\text { Control dalam proses kontrak } \\
\text { sering menumpuk karena admin } \\
\text { menginput data secara manual, } \\
\text { dari WhatsApp ke surat kontrak }\end{array}$ & $\begin{array}{l}\text { Memberikan kemudahan untuk } \\
\text { me-manage kontrak dengan } \\
\text { pengisian data secara mandiri } \\
\text { oleh author }\end{array}$ \\
\hline
\end{tabular}




\begin{tabular}{|l|l|l|} 
Efficiency & $\begin{array}{l}\text { Banyak waktu terbuang karena } \\
\text { mengisi data ke surat kontrak } \\
\text { secara manual }\end{array}$ & $\begin{array}{l}\text { Memanajemen waktu lebih } \\
\text { singkat dan akurat }\end{array}$ \\
\hline Service & $\begin{array}{l}\text { Sistem sekarang masih } \\
\text { menggunakan WhatsApp } \\
\text { sebagai media penghubung } \\
\text { antara admin dan author dalam } \\
\text { hal meminta data. }\end{array}$ & $\begin{array}{l}\text { author dapat login dan submit } \\
\text { di website data pribadi dan } \\
\text { melihat proses kontrak yang } \\
\text { sedang diajukan. }\end{array}$ \\
\hline
\end{tabular}

\section{ANALISIS PROSEDUR SISTEM BERJALAN}

\section{Use Case Diagram yang berjalan}

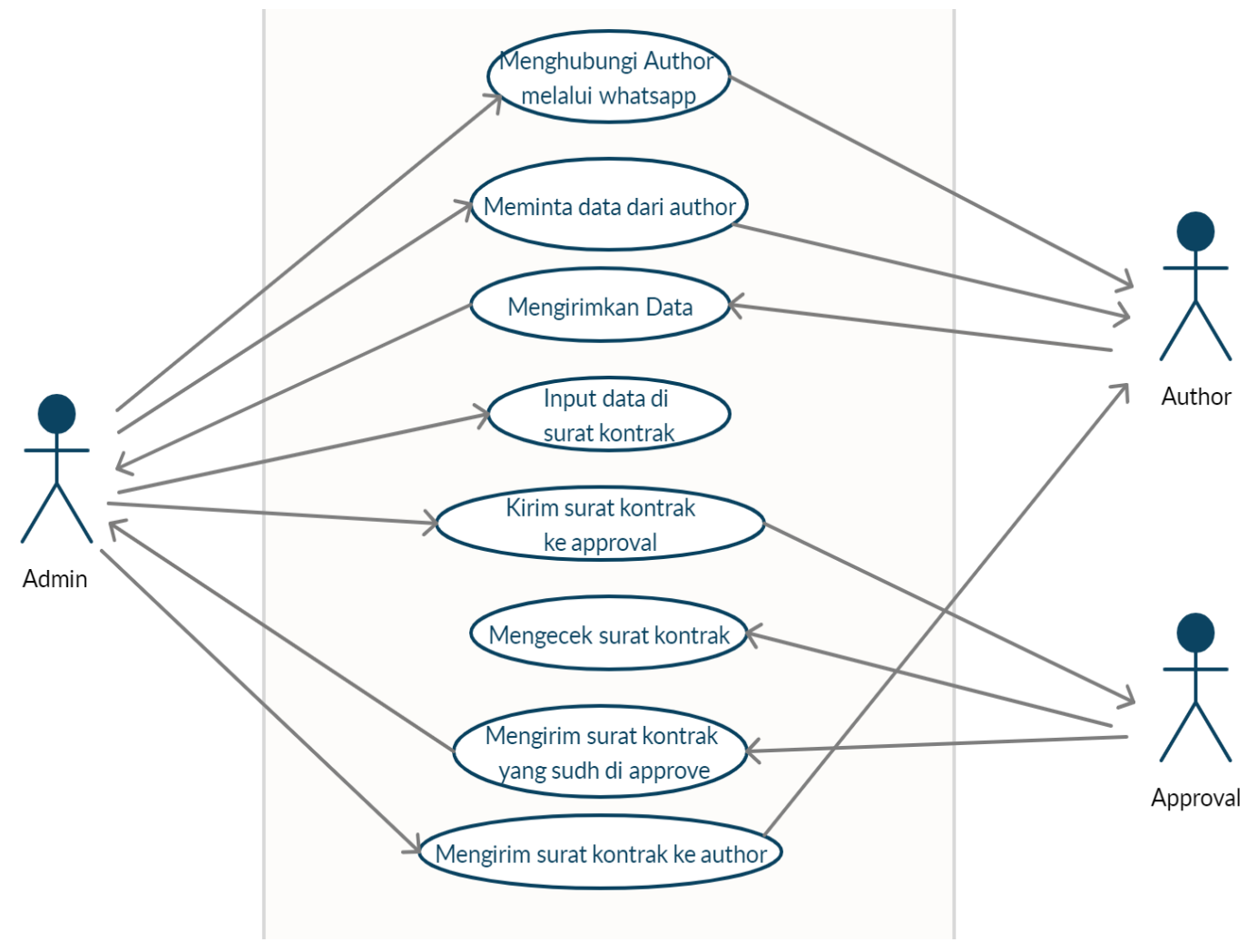

ANALISIS PROSEDUR SISTEM USULAN 


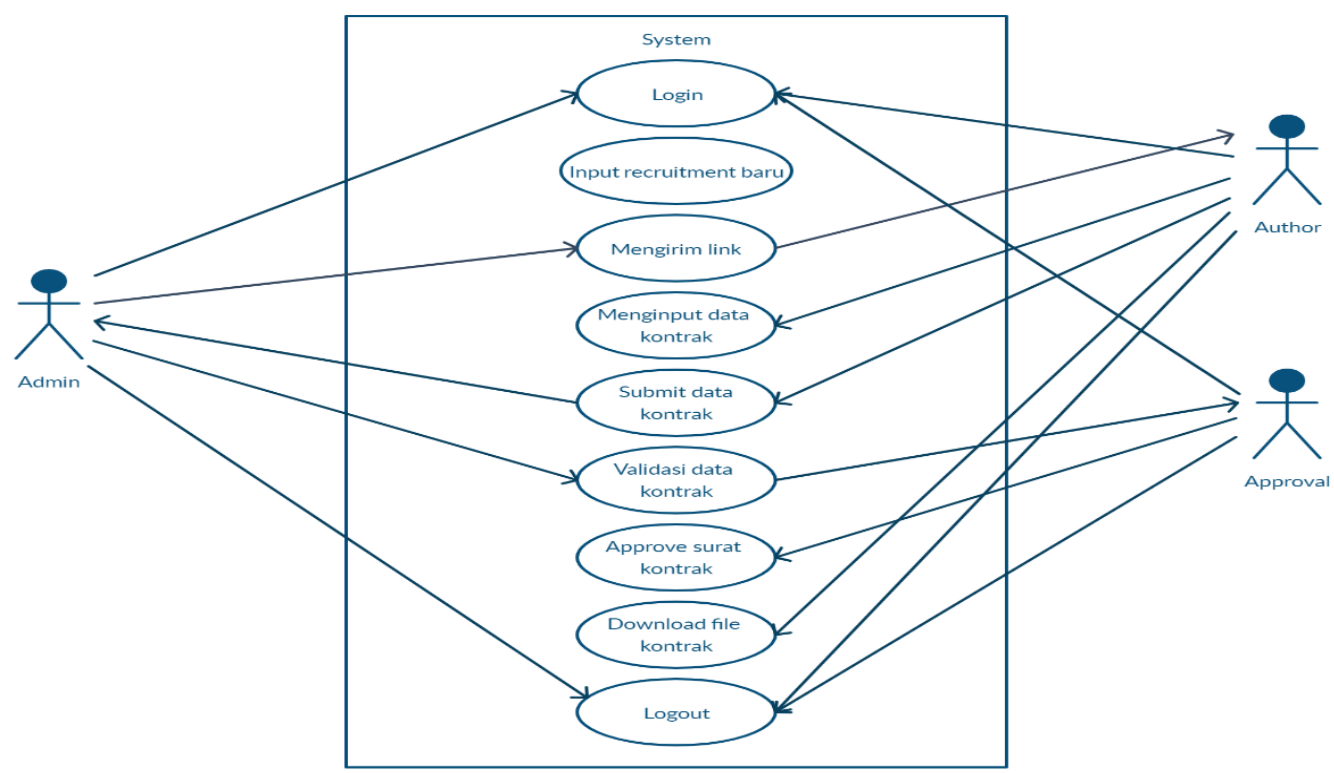

Usecase Diagram yang diusukan

Activity Diagram sistem yang telah diusulkan

1. Activity Diagram pada Admin 
ISSN: 2461-1409

Online ISSN: 2655-5298

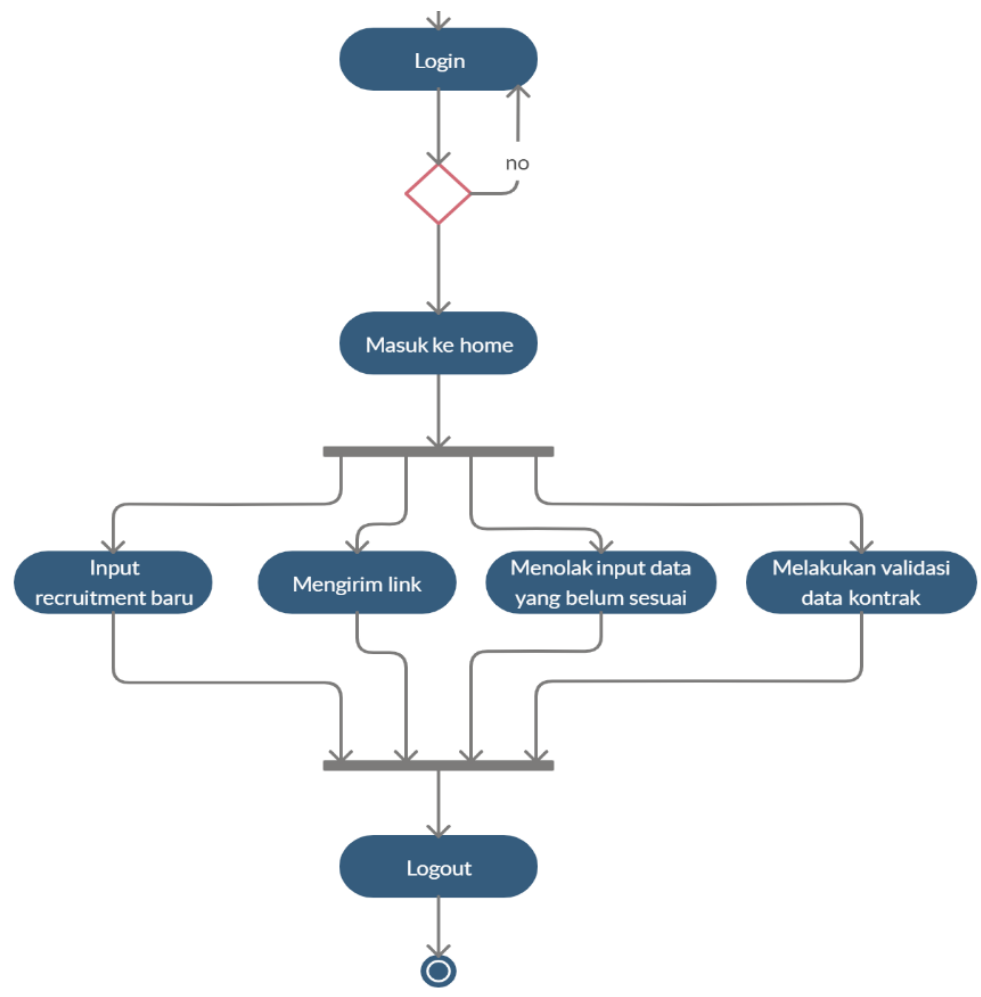

2. Activity Diagrampada Author 
ISSN: 2461-1409

Online ISSN: 2655-5298

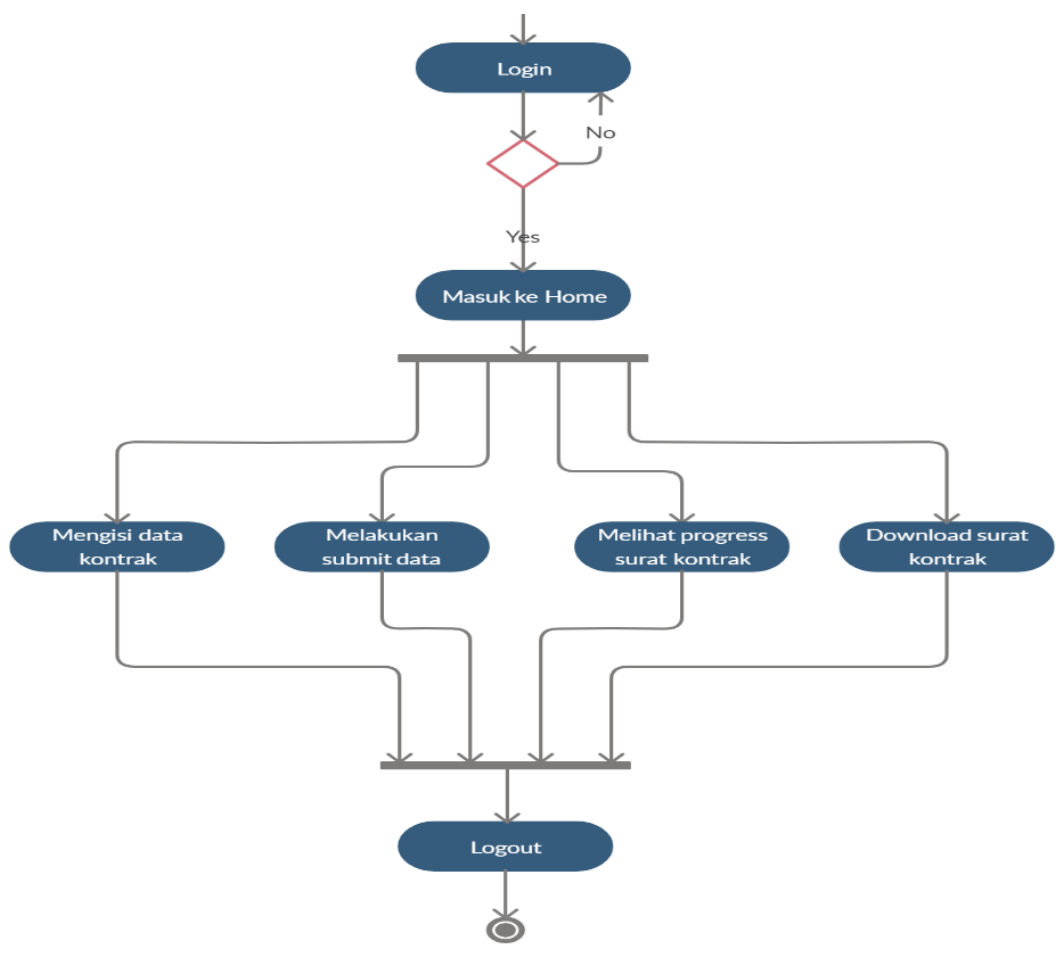

3. Activity Diagrampada Approval

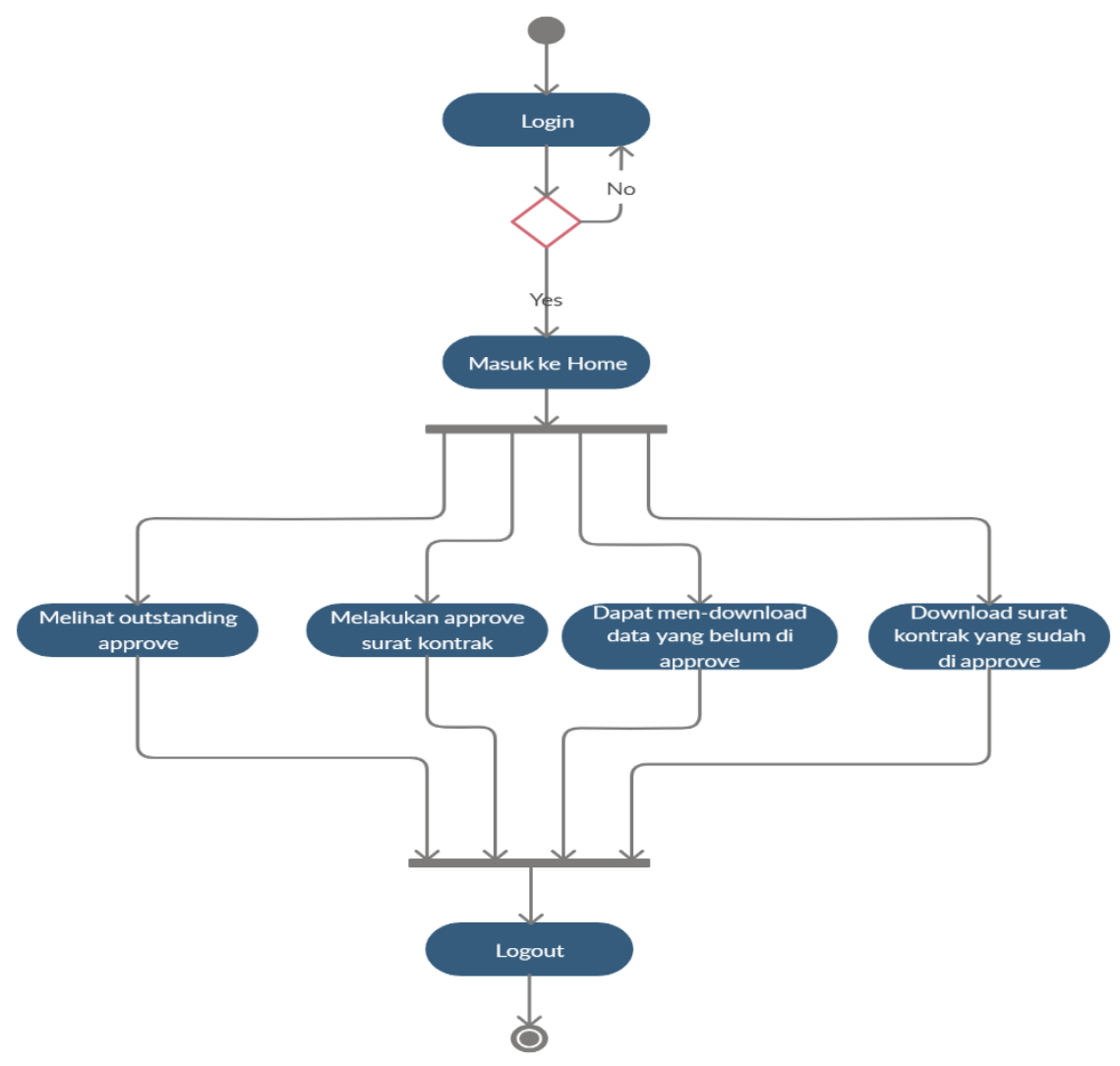




\section{IMPLEMENTASI}

Untuk mengakses website sistem usulan, admin akan mengirimkan link agar author dapat signup dan sign in ke dalam website dan dapat mengisi data kontrak

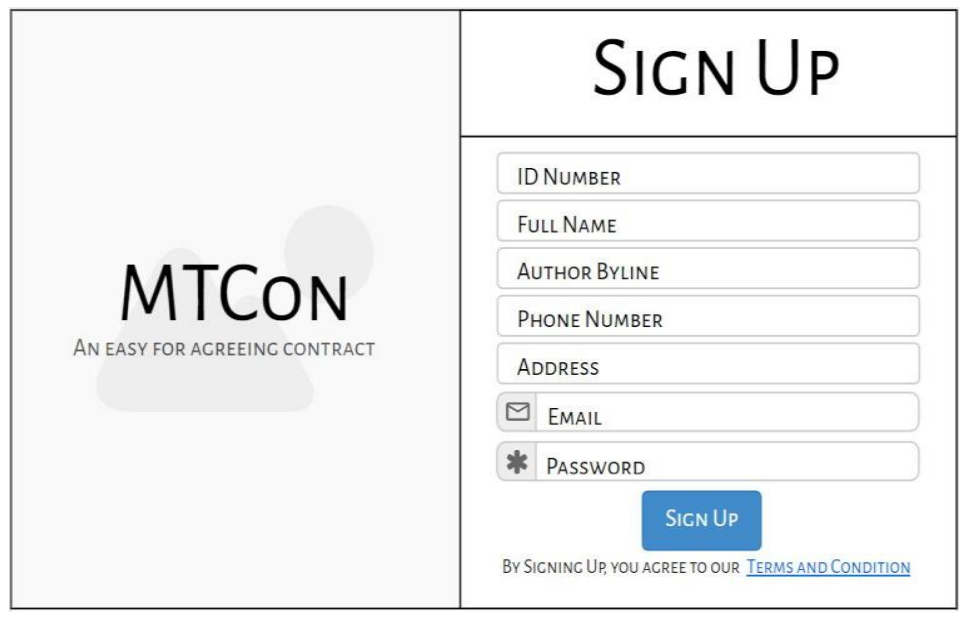

Gambar 1. Tampilan Sign Up

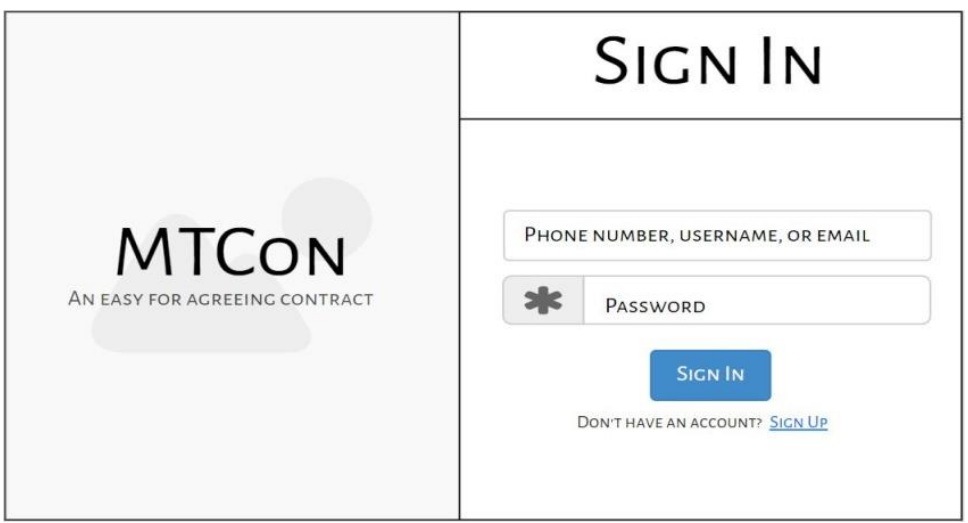

Gambar 2. Tampilan Sign In

Tampilan home digunakan oleh seluruh actor, terutama author sebagai media informasi mengenai kontrak dan bagaimana sistem memproses kontrak Menu home adalah tampilan yang berisi penjelasan apa itu MT Con. Menu features berisi penjelasan fitur apa saja yang dapat dilakukan oleh website yang dirancang. Menu profile berisi text box yang hanya bisa diisi setelah author sign up dan sign in. Menu contact berisi kontak admin dan email perusahaan. 
ISSN: 2461-1409

Online ISSN: 2655-5298

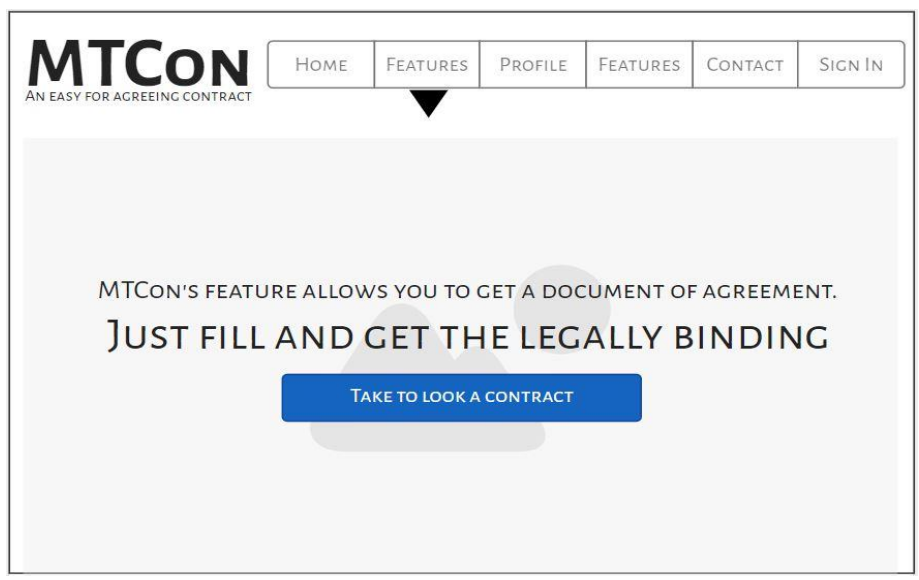

Gambar 3. Tampilan Home

Author yang telah sigun up dan login akan diarahkan ke dashboard untuk pengisian data kontrak. Authorsubmit data agar sampai ke admin untuk divalidasi.

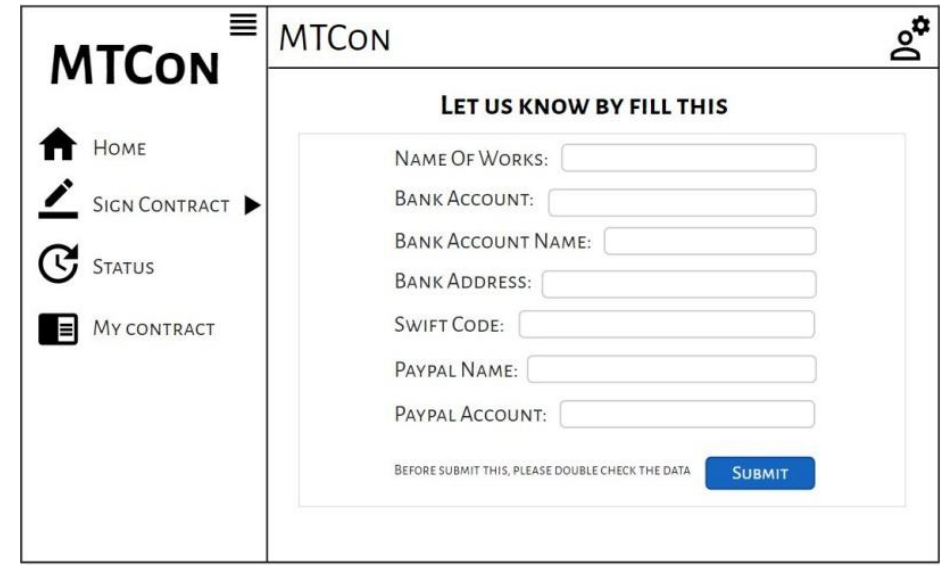

Gambar 4. Dashboard Sign Contract

Author dapat melihat status surat kontrak, sedangkan admin akan memvalidasi, apakah isi data tersebut sudah benar atau belum. Kalau sudah divalidasi, approval akan mendapat data terbaru untuk memproses surat kontrak. 
ISSN: 2461-1409

Online ISSN: 2655-5298

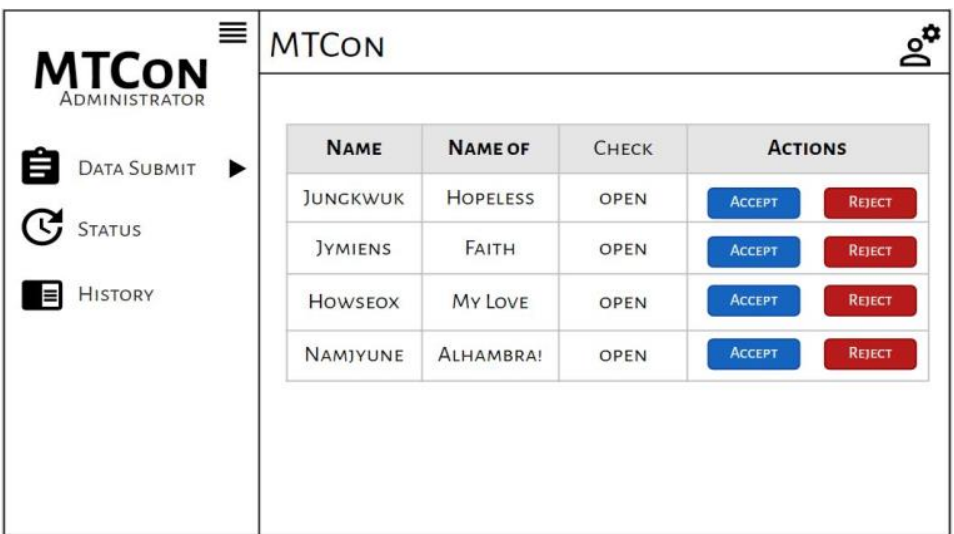

Gambar 5. Dashboard data yang disubmit

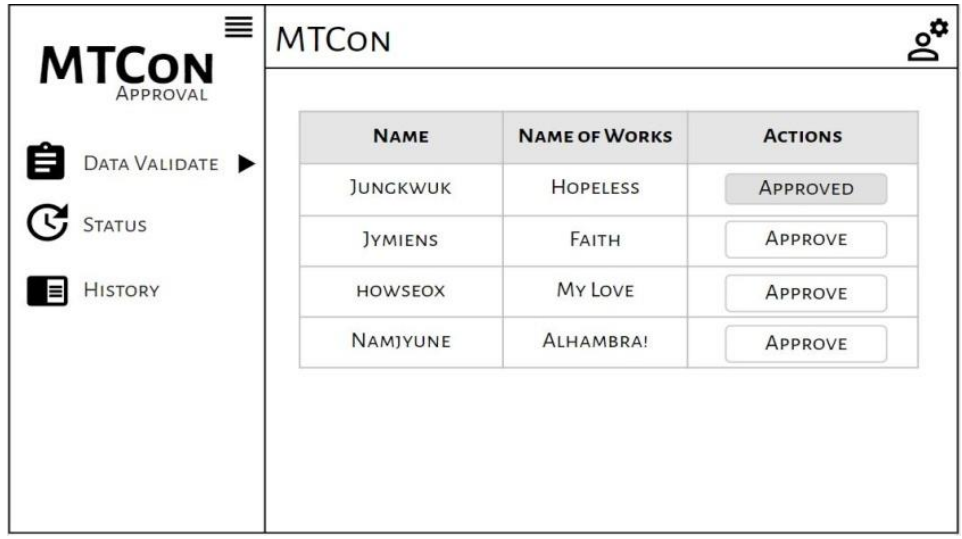

Gambar 6. Dashboard validasi data oleh approval

Setelah sudah di approved, surat kontrak dapat di download oleh author, sedangkan admin dan approval dapat mendownload juga melihat history surat kontrak.

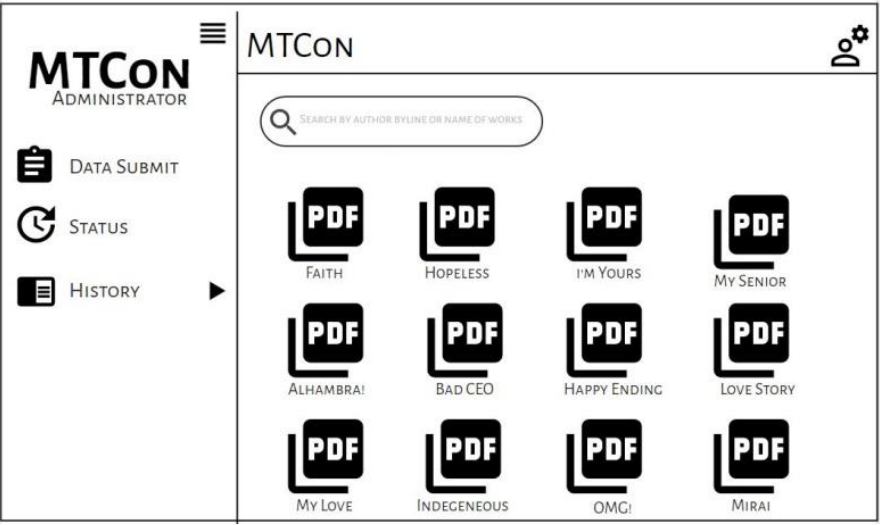

Gambar 7. Dashboard history 


\section{KESIMPULAN}

a. Sistem penerimaan kontrak novel pada aplikasi Manga Toon saat ini sudah berjalan dengan baik dan memudahkan, juga memberikan manfaat bagi pengguna maupun staf, namun masih kurang dari segi efisiensi waktu. Proses pembuatan surat kontrak masih diinput secara manual oleh admin, bahkan proses print, cap perusahaan dan scan masih dilakukan satu persatu oleh approval.

b. Proses penerimaan kontrak novel pada aplikasi Manga Toon yang telah berjalan saat ini dinilai efektif dan efisien dalam pengaksesan sehingga dapat menghasilkan keluaran sebuah karya yang dikontrak yang bagus dan berkualitas.

\section{SARAN}

Disarankan agar sistem yang telah dibuat dapat dimanfaatkan sebaik-baiknya oleh platform Manga Toon.

Disarankan agar sistem ini dapat dikembangkan lebih lanjut agar menjadi website yang sempurna.

\section{DAFTAR PUSTAKA}

[1] Rusmawan, Uus. 2019. Teknik Penulisan Tugas Akhir Dan Skripsi Pemrograman. Jakarta: PT. Elex Media Komputindo.

[2] Setiani, Ageng, Meidy Surya Hadi Putra, Winda Larasati. 2015. Smart HomeAutomatic menggunakan media bluetooth berbasis mikrokontroler atmega 328. Jurnal CCIT Vol 8 No.3-Mei 2015 ISSN: 1978-828.Tangerang: Perguruan Tinggi Raharja.

[3] Djahir, Yulia, dan Dewi Pratitia. 2015. Bahan Ajar Sistem Informasi Manajemen. Yogyakarta: Deepublish Publisher.

[4] Yuliana, Khozin,Harfizar danMuhAfiffudin.2017.Perancangan Sistem Informasi Pendataan Karyawan Pada Perusahaan Jasa Berbasis WEB. Jurnal SENSI Vol. 3 No. 2-Agustus 2017 ISSN: 2461-1409. Tangerang: Perguruan Tinggi Raharja.

[5] Soegianto, Agoes. 2018. Penulisan Karya Ilmiah untuk Jurnal Internasional Bereputasi. Surabaya: Airlangga University Press.

[6] Kriyantono, Rachmat. 2014. Teori-Teori Public Relations Perspektif Barat \& Lokal: Aplikasi Penelitian dan praktik. Jakarta: Penerbit Kencana. 
[7] M Arafat Imam G, Kim-Ara 김아라, Kim-Ara. 2016. Book of Mentor [Bundling 4 in 1]: Leader University, The Art of Meeting. Kim-Ara Holding Group.

[8] Richard Stim, Attorney. 2016. Contract: The Essential Business Desk Reference. Berkeley, California: Nolo.

[9] Ezeigbo, Benita. 2017. E-Contract. Essentials, Variety and Legal Issues. Jerman: GRIN Verlag

[10] Puspaningrum, Galuh. 2018. Konseptualisasi Pengaturan E-Contract Di Indonesia. Research Gate.

[11] Tripathy, Biswajit, Jibitesh Mishra. 2018. A Novel Approach of Study of Universal E-Contract Framework for Ecommerce. International Journal of E-Services and Mobile Applications (IJESMA) Vol 10.

[12] Husni, Emir, Bramanto Leksono, dan Muhammad Ridho Rosa. 2015. Digital signature for contract signing in service commerce.TIME-E. 7389757.

[13] Tripathy, Biswajit, Jibitesh Mishra. 2017. A Generalized Framework for EContract. International Journal of Service Science, Management, Engineering, and Technology (IJSSMET) Vol 8.

[14] Jain, Himanshu, P. Radha Krishna, Kamalakar Karlapalem. 2016. ContextAwareWorkflow Execution Engine for E-Contract Enactment. International Conference on Conceptual Modeling Vol 9974. 